\title{
Indicadores de vulnerabilidade da seca e avaliação da governança de 1991-2010 no semiárido Paraibano
}

O desenvolvimento de indicadores de vulnerabilidade da seca e a avaliação da governança no semiárido é de fundamental importância para que se possa busca alternativas para melhorar as condições de vida da população. Assim, objetivou-se este estudo desenvolver indicadores de vulnerabilidade à seca e avaliar a governança, no período de 1991 a 2010, em parte do Cariri Oriental municípios de Alcantil e São João do Cariri, semiárido Paraibano. O trabalho foi desenvolvido em dois municípios do semiárido paraibano da microrregião do Cariri Oriental (Alcantil e São João do Cariri), os dados para confecção dos indicadores foram obtidos das planilhas do Programa das Nações Unidas para o Desenvolvimento (PNUD). Foram desenvolvidos índice com base na capacidade adaptativa (políticoinstitucional) composto por indicador de vulnerabilidade e governança; demografia e IDHM; sensibilidade (socioeconômica) formado pelos indicadores renda trabalho e habitação e exposição (sociocultural) composta pelo indicador educação. Cada indicador possui subindicadores formado por fatores escolhidos de acordo com cada município estudado comparando com os dados em nível de Brasil. Os indicadores de vulnerabilidade à seca e governança desenvolvidas são capazes de diagnosticar a situação da população da região semiárida paraibana, e apontar quais estratégias de governança tem sido utilizado para mitigar a vulnerabilidade. Os municípios do Cariri paraibano, mais precisamente Alcantil e São João do Cariri quando se compara 1991 a 2000 e 2000 a 2010 , são considerados vulneráveis a seca, pois as estratégias de governança a seca adotas ainda não são suficientes para suprir todos os problemas. As principais estratégias de governança adotadas em Alcantil e São João do Cariri são Bolsa família, Benefício de prestação continuada, luz para todos, empregos em órgãos públicos e o programa saúde da família.

Palavras-chave: Escassez de Água; Sistema Socioecológicos; Ações Governamentais; Fragilidades.

\section{Vulnerability indicators and 1991-2010 drought governance assessment in the semi-arid of Paraíba}

\begin{abstract}
The development of indicators of vulnerability to drought and the assessment of governance in the semiarid region is of fundamental importance in order to seek alternatives to improve the living conditions of the population. Thus, the objective of this study was to develop indicators of vulnerability to drought and to assess governance, in the period from 1991 to 2010, in of the Cariri Oriental municipalities of Alcantil and São João do Cariri, semi-arid region of Paraíba. The work was carried out in two municipalities in the semi-arid region of Paraiba in the Cariri Oriental micro-region (Alcantil and São João do Cariri), the data for making the indicators were obtained from the spreadsheets of the United Nations Development Program (UNDP). An index was developed based on the adaptive capacity (political-institutional) composed of an indicator of vulnerability and governance; demography and MHDI; sensitivity (socioeconomic) formed by the indicators income, work and housing and exposure (sociocultural) composed by the education indicator. Each indicator has sub-indicators formed by factors chosen according to each municipality studied compared to data at the level of Brazil. The indicators of vulnerability to drought and governance developed are able to diagnose the situation of the population in the semi-arid region of Paraiba, and point out which governance strategies have been used to mitigate vulnerability. The municipalities of Cariri Paraiba, more precisely Alcantil and São João do Cariri when comparing 1991 to 2000 and 2000 to 2010, are considered vulnerable to drought, since the drought governance strategies adopted are still not enough to supply all the problems. The main governance strategies adopted in Alcantil and São João do Cariri are Bolsa Família, Benefit of continued provision, light for all, jobs in public agencies and the family health program.
\end{abstract}

Keywords: Water Shortage; Socio-Ecological System; Governmental Actions; Weaknesses.

Topic: Desenvolvimento, Sustentabilidade e Meio Ambiente

Reviewed anonymously in the process of blind peer

Sara Henrique Pontes Nunes (D)

Instituto Federal de Pernambuco, Brasil http://lattes.cnpq.br/6125808809193141 http://orcid.org/0000-0001-5387-8739

sarapontesufcg@gmail.com

\section{José Dantas Neto ID}

Universidade Federal de Campina Grande, Brasil http://lattes.cnpq.br/9137226205129315 http://orcid.org/0000-0003-0798-6717

\section{zedantas1955@gmail.com}

Patrícia Ferreira da Silva

Universidade Federal de Campina Grande, Brasil

http://lattes.cnpq.br/8146309314429987

http://orcid.org/0000-0002-4580-2336

patrycyafs@yahoo.com.br

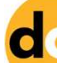

DOI: 10.6008/CBPC2179-6858.2020.003.0018
Received: $14 / 03 / 2020$ Approved: 20/04/2020

\author{
Elder Guedes dos Santos \\ Universidade Federal de Campina Grande, Brasil \\ http://lattes.cnpq.br/0005084000543540 \\ http://orcid.org/0000-0002-3804-9745 \\ elder.ufcg@gmail.com \\ Rigoberto Moreira de Matos (iD) \\ Universidade Federal de Campina Grande, Brasil \\ http://lattes.cnpq.br/9976807429777592 \\ http://orcid.org/0000-0003-3455-9876 \\ rigobertomoreira@gmail.com
}

\section{Referencing this:}

NUNES, S. H. P.; DANTAS NETO, J.; SILVA, P. F.; SANTOS, E. G.; MATOS, R. M.. Indicadores de vulnerabilidade da seca e avaliação da governança de 1991-2010 no semiárido Paraibano. Revista Ibero Americana de Ciências Ambientais, v.11, n.3, p.210-228, 2020. DOI: http://doi.org/10.6008/CBPC2179-6858.2020.003.0018 


\section{INTRODUÇÃO}

As condições adversas encontradas no semiárido do nordeste Brasileiro entre elas os fatores agroclimáticos, edáficos e a vegetação interagem juntamente com as ações antrópicas negativas causando vulnerabilidade social, ambiental e econômica para a população da região (MARENGO et al., 2011). Soares et al. (2012) relatam que são diversas as interpretações para o termo vulnerabilidade, contudo, as ideias se entrelaçam na tentativa de descrever a capacidade de um sistema socioecológicos em lidar com condições de estresse de modo geral vinculado a um evento climático (seca, inundação, terremoto, furacão dentre outros). Nesse sentido, El Zein et al. (2015) afirmam que a vulnerabilidade costuma ser conceituada a partir da exposição ou grau intensidade do estresse; da sensibilidade ou grau de resposta ao estresse e a capacidade adaptativa que representa a habilidade do sistema para se ajustar às mudanças climáticas.

Quando se trata de indicadores de vulnerabilidade vinculados a condição de seca no semiárido do nordeste brasileiro, os problemas estão associados a irregularidades da precipitação temporal e espacial, fato que promove elevadas taxas de evapotranspiração, as quais são responsáveis pela perda de água dos mananciais, plantas e solo. Além disso, essa região tem como a predominância de solos com baixa fertilidade, rasos e formados por rochas cristalinas que contribui para baixa retenção de água, sendo grande parte perdida por percolação (ANDRADE et al., 2017).

Caccimali et al. (2014) destacam que a vulnerabilidade se torna ainda mais evidente no semiárido do nordeste brasileiro em decorrência das famílias dependeram da transferência de renda de programas federais, economia sem dinâmica, sendo a agropecuária a principal fonte de emprego e renda o que confere baixa diversidade socioeconômica para a região. Situação este presente na maioria dos municípios paraibanos em que a atividade agropecuária apresentar uma baixa produtividade, muitas vezes acentuada pelo clima não favorável (em períodos de seca) e em outras vezes pela falta de técnicas mais especializadas, que são problemas mais de origem social, econômico e político, ela tem sido de grande importância para a economia paraibana (TARGINO et al., 2014).

Segundo o MMA (BRASIL, 2016) a falta de recursos humanos e financeiros limita a capacidade da população em lidar com os perigos ambientais (ANDRADE et al., 2013) e favorece processos de degradação ambiental. Nos últimos anos a região semiárida do nordeste do Brasil vem enfrentando mudanças nos recursos naturais da região, como perda da biodiversidade, redução da fertilidade natural dos solos, poluição dos mananciais e avanços na desertificação, fatores estes que alteram o ecossistema local e convergem para o agravamento da situação de vulnerabilidade, necessitando de medidas relacionadas a governança política, ambiental, social, cultural e econômica.

Nesse sentido, para que a vulnerabilidade à seca seja superada pelos municípios do semiárido brasileiro se faz necessário a integração dos atores nos setores público e/ou privado, com o objetivo de criar oportunidades ou resolver problemas de cunho social, utilizando instituições e ações governamentais, dentro de uma base normativa criada para o desenvolvimento dessas atividades, ou seja, a vulnerabilidade pode ser superada ou amenizada com ações de governança (KOOIMAN, 2013; RAKODI, 2013). 
Para a formação do processo de governança, faz-se necessário definir possíveis parceiros que tem algum tipo de influência no processo de governança, e por este motivo são escolhidos para fazer parte e pôr em prática as políticas socioambientais necessárias (GRODZI'NKA-JURCZAK et al., 2007). Dada à relevância, para a temática relaciona a vulnerabilidade da seca e avaliação da governança no semiárido do Brasil dentro do contexto de mudança do clima, nota-se que estudos relacionados a seca apenas tratam do aspecto físico, deixando a desejar no contexto da geração de indicadores socioculturais, socioeconômicos e político institucionais, observando o cunho social, para mensurar a evolução da governança frente a seca, considerando que esta é a categoria de desastres naturais com maior registro de ocorrências no semiárido do país. Assim sendo, objetivou-se com este estudo desenvolver indicadores de vulnerabilidade à seca e avaliar a governança, no período de 1991 a 2010, em parte do Cariri Oriental cidades de Alcantil e São João do Cariri, semiárido Paraibano.

\section{MATERIAIS E MÉTODOS}

\section{Caracterização da área de estudo: Cariri Oriental (Alcantil e São João do Cariri)}

A população do Cariri Oriental semiárido Paraibano é de aproximadamente 80.851 hab., em uma área de $8.214 \mathrm{Km}^{2}$, sua densidade demográfica fica em torno de 9,84 habitantes por quilometro quadrado e um pouco mais da metade residente na área urbana (IBGE, 2017). O território do Cariri Oridental encontrase na porção centro-sul do Estado da Paraíba, entre as coordenadas de $7^{\circ}$ e $8^{\circ} 30^{\prime}$ latitude sul e $36^{\circ}$ e $37^{\circ} 30^{\prime}$ de longitude oeste, com altitude para níveis de 400 a 600 metros (Figura 1).

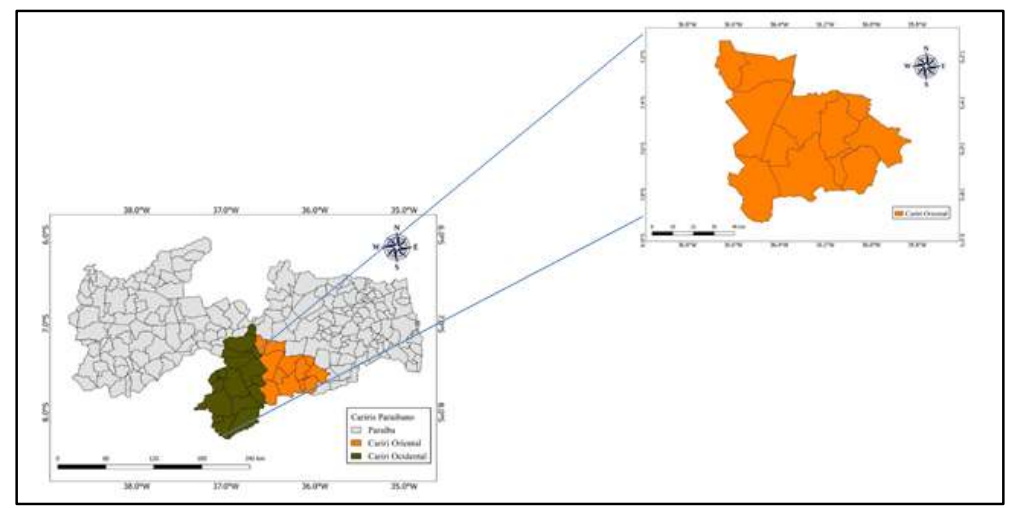

Figura 1: Mapa de localização da região Cariri Oriental Semiárido Paraibano.

O clima predominante na região do Cariri segundo a classificação de Köppen é Bsh-Semiárido Quente com chuvas de verão e outono (FRANCISCO, 2010). A precipitação média anual do Cariri Paraibano fica entre 350 e 700 mm, o que é considerado uma precipitação média anual muito baixa, os períodos de seca podem persistir por até onze meses. A vegetação típica da região é a caatinga arbustiva-herbácea é a formação vegetal mais comum, algumas espécies encontradas são a jurema, o facheiro e a macambira. A maioria dos solos são rasos e pedregosos em áreas de relevo acidentado e tem os maiores níveis de degradação, quando ficam descobertos apresentam fortes sinais de erosão (IBGE, 2017). 


\section{Município de Alcantil}

Alcantil é um município brasileiro do estado da Paraíba, pertencente a região metropolitana de Campina Grande, incluída na área de abrangência do semiárido nordestino, tendo como critérios para esta inclusão os índices pluviométrico, de aridez e o de risco de seca. Localizado na mesorregião da Borborema e microrregião do Cariri Oriental, com uma área de $306,89 \mathrm{Km}^{2}$ e uma população, segundo o censo de 2010, de 5.239 hab. (Figura 2). Sua densidade demográfica é de 17,07 hab. $\mathrm{Km}^{-2}$, seu IDHM é considerado baixo variando entre 0,500 e 0,599.

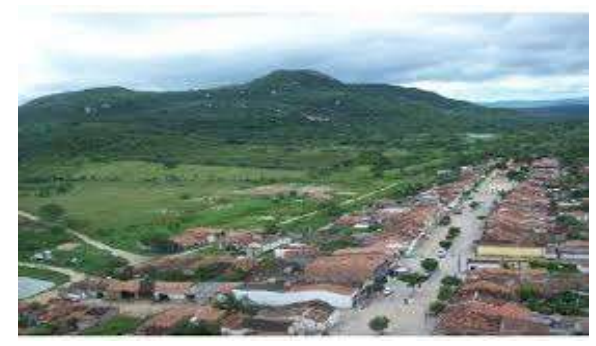

Figura 2: Município de Alcantil. Fonte: IBGE (2016).

A vegetação do município é composta por Floresta Caducifólia, Cerrado e Caatinga. Em relação aos solos há topos de relevos arredondados e vertentes íngremes ocorrem os solos do tipo litólico, rasos pedregosos e fertilidade natural média. O potencial de água subterrânea é quase sempre baixo a muito baixo, de qualidade questionável.

\section{Município de São João Do Cariri}

São João do Cariri é um município brasileiro do estado da Paraíba, da região do semiárido. Pertencente a mesorregião da Borborema e microrregião do Cariri Oriental. Com uma população, de acordo com o censo de 2010, de 4.344 hab. (Figura 3). Em uma área de 656,57 $\mathrm{Km}^{2}$ sendo sua densidade demográfica de 6,62 hab. $\mathrm{Km}^{-2}$ e seu IDHM é considerado médio ficando entre 0,600 e 0,609.

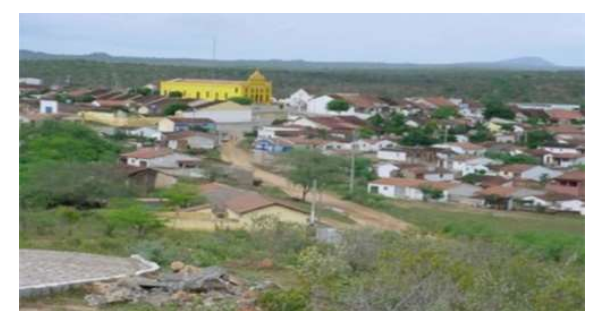

Figura 3: Município de São João do Cariri.

Sua vegetação é caracteriza-se por apresentar uma vegetação baixa, muito espaçada e um solo raso, arenoso e seco, sendo predominante a caatinga, repleta de cactáceas, pedregulhos e serrotes. E o macro relevo é a Superfície Aplainada do Planalto da Borborema, esculpida sobre litologia cristalina. O município de alcantil fica está situado nas coordenadas geográficas: Latitude: $7^{\circ} 44^{\prime} 5^{\prime \prime}$ Sul, Longitude: $36^{\circ} 4^{\prime}$ $33^{\prime \prime}$ Oeste. Já São João do Cariri fica nas coordenadas geográficas: Latitude: $7^{\circ} 23^{\prime} 27^{\prime \prime}$ Sul, Longitude: $36^{\circ} 32^{\prime}$ 2" Oeste (Figura 4). 


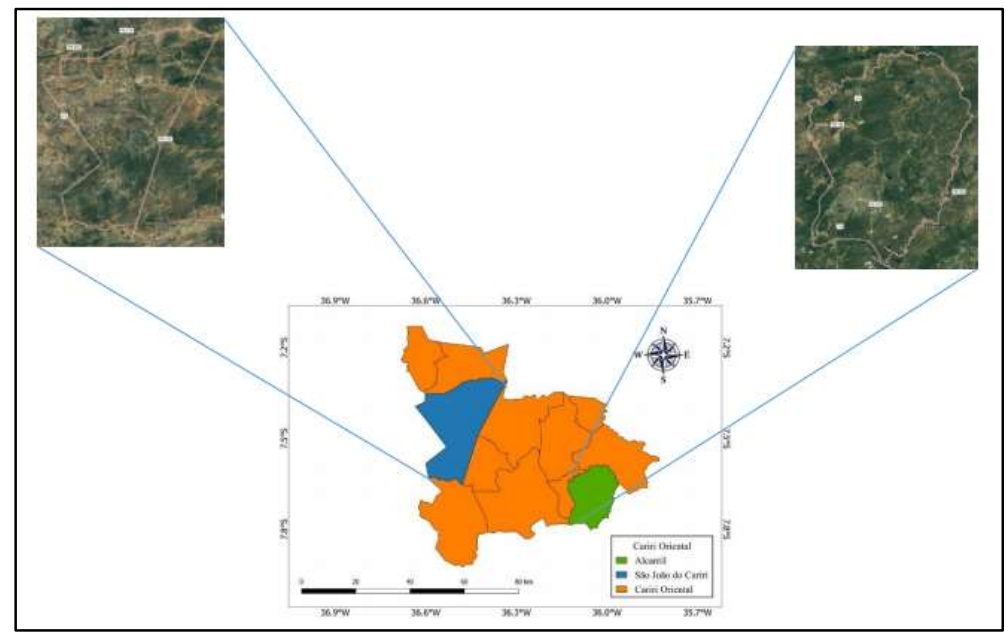

Figura 4: Mapa dos municípios de Alcantil e São João do Cariri.

\section{Desenvolvimento dos indicadores}

A metodologia utilizada para o desenvolvimento dos indicadores de vulnerabilidade foi adaptada de (BHATTACHARYA et al., 2007), onde o desenvolvimento dos indicadores e subindicadores foi baseado em três variáveis são elas: Capacidade adaptativa aquelas relacionadas a questão político-institucional, sensibilidade as que envolvem os fatores socioeconômicos e a exposição os vinculados aos índices socioculturais no período de 1991 a 2010 (Tabela 1). Essa alteração se deu em decorrência da necessidade de variáveis que fossem pertinentes a problemática estudada, que neste caso é uma avaliação da evolução da governança frente a vulnerabilidade causada pela seca no semiárido. A base para a criação dessas novas variáveis surgiu a partir dos indicadores de governança estabelecidos pelo banco mundial.

Tabela 1: Variáveis, indicadores e subindicadores de vulnerabilidade para o semiárido paraibano mais especificamente o Cariri Oriental municípios de Alcantil e São João do Cariri período de 1991 a 2010.

\begin{tabular}{|c|c|c|c|c|}
\hline & Variáveis estudadas & Indic & r de Vulnerabilidade & Subindicador de vulnerabilidade \\
\hline \multirow{14}{*}{ 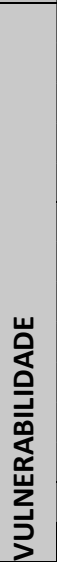 } & \multirow{5}{*}{ 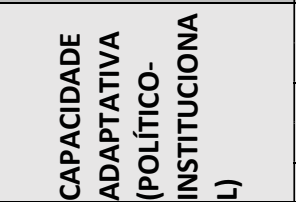 } & \multirow{2}{*}{ (1) } & \multirow{2}{*}{ Vulnerabilidade e Governança } & 1A - Habitação \\
\hline & & & & 1B - Educação, Trabalho e renda \\
\hline & & \multirow[t]{2}{*}{ (2) } & \multirow[t]{2}{*}{ Demografia } & 2A - Mortalidade infantil \\
\hline & & & & 2B - Probabilidade de sobrevivência até 60 anos \\
\hline & & (3) & IDHM & $3 \mathrm{~A}-\mathrm{IDHM}$ \\
\hline & \multirow{7}{*}{ 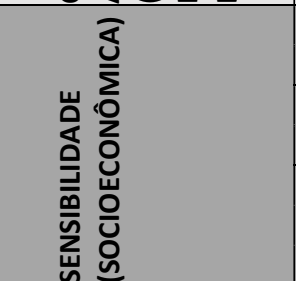 } & \multirow[t]{2}{*}{ (1) } & \multirow[t]{2}{*}{ Renda } & 1A- Renda per capita \\
\hline & & & & 1B - Índice de Gini \\
\hline & & \multirow{2}{*}{$(2)$} & \multirow{2}{*}{ Trabalho } & 2A - Escolaridade \\
\hline & & & & 2B-Setor \\
\hline & & \multirow{3}{*}{ (3) } & \multirow{3}{*}{ Habitação } & 3A - Porcentagem da população com água encanada \\
\hline & & & & 3B -População em domicílios com coleta de lixo \\
\hline & & & & 3C - População em domicílios com energia elétrica \\
\hline & \multirow{2}{*}{ 은 出。 } & \multirow{2}{*}{ (1) } & \multirow{2}{*}{ Educação } & $1 \mathrm{~A}$ - Evolução da população exposta ao analfabetismo \\
\hline & & & & 1B- Porcentagem da escolaridade \\
\hline
\end{tabular}

Fonte: Adaptado de Bhattacharya et al. (2007).

\section{Obtenção dos indicadores e subindicadores da variável capacidade adaptativa (político-institucional)}

O indicador vulnerabilidade formado pelo subindicador Habitação - 1A foi composto pelos dados em percentual de pessoas em domicílios sem energia elétrica (\%PDSEE) e de pessoas em domicílios com abastecimento de água e esgotamento sanitário inadequados (\%PDCAAESI). Já o subindicador Educação, Trabalho e renda $-1 B$, referente as pessoas em domicílios vulneráveis à pobreza e sem ensino fundamental 
completo (PDVPSEFC) e pessoas de 15 a 24 anos que não estudam, não trabalham e são vulneráveis (PNENTSV 15 a 24 anos) paras os anos de 1991; 2000 e 2010, respectivamente.

O indicador de vulnerabilidade e governança demografia foi formado pelos subindicadores mortalidade Infantil (MI) e probabilidade de sobrevivência de idosos (PS). Indicador IDHM do Brasil, comparado aos municípios do semiárido paraibano Alcantil e São João do Cariri paras os anos de 1991; 2000 e 2010.

\section{Obtenção dos indicadores e subindicadores da sensibilidade (socioeconômica)}

Indicador renda formado pelos subindicadores pobreza composto por percentual de indivíduos extremamente pobres (IEP) e percentual de indivíduos de vulneráveis à pobreza (PIVP). Já o indicador renda formado pelos subindicadores desigualdade composto por Percentual da renda apropriada pelos $80 \%$ mais pobres (PRA 80\% mais pobres) e percentual da renda apropriada pelos 10\% mais ricos (PRA 10 mais ricos) do Brasil, comparado aos municípios do semiárido paraibano Alcantil e São João do Cariri paras os anos de 1991; 2000 e 2010.

O indicador trabalho formado pelo subindicador escolaridade composto por percentual dos ocupados com ensino médio completo - 18 anos ou mais (POEMC) e percentual dos ocupados com ensino superior completo - 18 anos ou mais (POESC). Já para subindicador setor este foi composto por percentual dos ocupados no setor agropecuário - 18 anos ou mais (POSA) e percentual dos ocupados na indústria de transformação - 18 anos ou mais (POIT) do Brasil, comparado aos municípios do semiárido paraibano Alcantil e São João do Cariri paras os anos de 1991; 2000 e 2010.

Com relação ao indicador habitação este foi formado pelo subindicador porcentagem da população com água encanada composto pelo percentual da população em domicílios com água encanada (PPDCAE), porcentagem da população em domicílios com coleta de lixo (PPDCL) e porcentagem da população em domicílios com energia elétrica (PPDCEE) do Brasil, comparado aos municípios do semiárido paraibano Alcantil e São João do Cariri paras os anos de 1991; 2000 e 2010.

\section{Obtenção dos indicadores e subindicadores da exposição (sociocultural)}

O Indicador educação foi formado pelo subindicador Evolução da população exposta ao analfabetismo composto pela taxa de analfabetismo - 11 a 14 anos (TA 11 a 14 anos) e taxa de analfabetismo - 25 a 29 anos (TA 25 a 29 anos). Já o indicador educação formado pelo subindicador Porcentagem da escolaridade composto pelo percentual dos ocupados com ensino fundamental completo - 18 anos ou mais (POCEFC 18 anos ou mais) e percentual dos ocupados com ensino médio completo - 18 anos ou mais (POCEMC 18 anos ou mais) do Brasil, comparado aos municípios do semiárido paraibano Alcantil e São João do Cariri paras os anos de 1991; 2000 e 2010.

\section{Análise dos dados}

Os indicadores foram normalizados com ponderação variando de 0 a 1 conforme (BHATTACHARYA 
et al., 2007) equação 1, também se efetuou a agregação simples para desenvolvimento de índices, utilizando médias geométricas e aritméticas que no final geram os índices de vulnerabilidade à seca.

$$
I=\frac{(M-x)}{(M-m)} \quad \text { Eq. } 1
$$

Em que: $M$ - representa o máximo de cada variável, $x$ - é o valor observado para as variáveis e $m$-refere-se o valor mínimo de cada variável.

Os dados de cada município estudado foram obtidos das planilhas do Programa das Nações Unidas para o Desenvolvimento (PNUD) e no site atlas Brasil. O processo de utilização das médias é bastante utilizado nos inúmeros índices de desenvolvimento humano aplicados no Programa das Nações Unidas para o Desenvolvimento (PNUD) e aplicado para avaliação de gestão nos diversos níveis governamentais.

A partir da mudança das três variáveis originais, também foi possível a alocação de indicadores e subindicadores referentes a essas variáveis, que mais se adaptassem as condições das cidades estudadas, indicadores estes que também foram escolhidos de acordo com o grau de importância para a população local. Após alocação dos indicadores e subindicadores as respectivas variáveis, foram coletados dados quantitativos referentes às três décadas estudadas, em sites oficiais, e a partir da avaliação deles pode-se fazer uma análise qualitativa sobre a evolução ou não nesses dois municípios.

\section{RESULTADOS E DISCUSSÃO}

\section{Indicador vulnerabilidade e governança formado pelo subindicador Habitação}

Analisando a variável capacidade adaptativa (político-institucional) para os municípios de Alcantil e São João do Cariri comparando-os com o Brasil formado pelo indicador dentro do subindicador habitação, composto pelos dados em percentual de pessoas em domicílios sem energia elétrica (\%PDSEE) e de pessoas em domicílios com abastecimento de água e esgotamento sanitários inadequados (\%PDCAAESI) para os anos de 19991, 2000 e 2010, respectivamente (Tabela 2), pode-se observar que o município de Alcantil teve uma redução no percentual de pessoas que não tinham energia elétrica em seus domicílios de 77,3\%, isso quando fez-se o comparativo entre 1991 e 2000. Já entre 2000 a 2010 o decréscimo deste percentual foi de 94\% (Tabela 2).

Tabela 2: Indicador vulnerabilidade e governança formada pelo subindicador Habitação composto pelos dados em percentual de pessoas em domicílios sem energia elétrica (\%PDSEE) e percentual de pessoas em domicílios com abastecimento de água e esgotamento sanitários inadequados (\%PDCAAESI) do Brasil, comparado aos municípios do semiárido paraibano Alcantil e São João do Cariri paras os anos de 1991; 2000 e 2010.

\begin{tabular}{|l|l|l|l|l|l|l|}
\hline $\begin{array}{l}\text { Comparativo do Brasil com } \\
\text { Municípios estudados }\end{array}$ & \multicolumn{3}{|l|}{ Indicador vulnerabilidade e governança formado pelo subindicador Habitação } \\
\cline { 2 - 8 } & $\begin{array}{l}\text { \% PDSEE } \\
\mathbf{( 1 9 9 1 )}\end{array}$ & $\begin{array}{l}\text { \% PDSEE } \\
\text { (2000) }\end{array}$ & $\begin{array}{l}\text { \% PDSEE } \\
\text { (2010) }\end{array}$ & $\begin{array}{l}\text { \%PDCAAESI } \\
\text { (1991) }\end{array}$ & $\begin{array}{l}\text { \%PDCAAESI } \\
\text { (2000) }\end{array}$ & $\begin{array}{l}\text { \%PDCAA } \\
\text { ESI } \\
\text { (2010) }\end{array}$ \\
\hline Brasil & 15,16 & 6,54 & 1,42 & 10,39 & 8,91 & 6,12 \\
\hline Alcantil (PB) & 58,5 & 13,24 & 0,7 & 62,84 & 60,42 & 53,36 \\
\hline São João do Cariri (PB) & 39,83 & 4,41 & 0,5 & 13,68 & 22,48 & 11,98 \\
\hline
\end{tabular}

Com relação ao município de São João do Cariri a redução foi da ordem de $88,9 \%$ do número de pessoas que não possuíam energia elétrica quando se comparou 1991 a 2000 . Já para 2000 a 2010 a esta diminuição $88,6 \%$. Nota-se que para São João do Cariri as reduções foram bem próximas considerando os 
dois períodos comparativos (Tabela 2).

Quando analisados os dados em nível de Brasil, constata-se que houve reduções de 1991 a 2000 de $56,8 \%$ e de 2000 a 2010 de 74,3\%, respectivamente (Tabela 2), reduções estas bem inferiores quando comparadas dos municípios do semiárido Paraibano para os mesmos períodos. Fato que se justifica em decorrência dos dados do Brasil levar em consideração na sua quantificação os grandes municípios, em muitos casos os pequenos municípios não entram nessa quantificação em nível de Brasil.

Essa redução no número de domicílios sem energia elétrica no Brasil e nos munícipios está atrelada ao programa do governo federal lançado em 2003, conhecido como Programa Nacional de Universalização do Acesso e Uso da Energia Elétrica - Luz para Todos que tinha como objetivo, reduzir em $80 \%$ o número de habitações sem eletricidade no País (IICA, 2011; IBGE, 2010; IEA, 2015). Segundo Oliveira (2013) a eletricidade contribui de forma decisiva para melhoria da qualidade de vida das pessoas, consistindo em um elemento propulsor para o desenvolvimento econômico de uma dada região.

Cabe salientar ainda que ambos os municípios tiveram evolução positiva, visto que os percentuais de pessoas sem energia elétrica reduziu de forma expressiva, demonstrando que houve investimentos nesse setor, fator que leva a uma governança, ou seja, a integração dos setores visando resolver problemas das comunidades, de forma a superar fatores de vulnerabilidade, visto que residências com energia elétrica é um dos mecanismos de relevância no enfrentamento a seca no semiárido, levando em consideração que com energia se pode cavar poços, colocar bombas para seccionar água e conduzir até as residências (RAKODI, 2013).

Com relação ao percentual de pessoas em domicílios com abastecimento de água e esgotamento sanitários inadequados (\%PDCAAESI), o município de Alcantil obteve uma redução de 3,85 e 11,68\%, respectivamente para 1991 comparado a 2000 e 2000 a 2010 (Tabela 2). Evidenciando que o município iniciou a adoção de medidas que vieram a reduzir o número de domicílios com abastecimento de água e esgotamento sanitário inadequado, contribuindo desta forma para solucionar mesmo que em partes os problemas e entraves relacionadas as vulnerabilidades perante a condição de seca.

Para o município de São João do Cariri no tocante ao percentual de pessoas em domicílios com abastecimento de água e esgotamento sanitários inadequados (\%PDCAAESI) foi possível verificar que entre os anos de 1991 e 2000 houve uma diferença percentual negativa de $-64,3 \%$, ou seja, quando se comparou estes anos em 1991 havia mais pessoas em domicílios com abastecimento de água e esgotamento sanitários inadequados do que no ano de 2000. Entretanto, a diferença voltou a ser positivo de 2000 a 2010, correspondendo a um percentual de $46,7 \%$ (Tabela 2). Isso demonstra que a partir de 2000 o município iniciou a adoção de medidas ligadas a governança que vieram a amenizar os problemas relacionadas a seca.

Quando se compararam os dois municípios estudados com os dados em nível de Brasil, nota-se que os valores no contexto de país para 1991 a 2000 e 2000 a 2010 foram de 14,2 e 31, 3\%, respectivamente. Estes por sua vez próximos aos que foram observados para os municípios, com poucas discrepâncias. Cabe salientar que o acesso aos serviços públicos de saneamento é indispensável para a saúde humana, a falta desses serviços pode acarretar uma série de doenças infecto parasitárias, além de tornar insalubres os 
agrupamentos humanos nos ambientes urbano e rural (BARRETO et al., 2011).

Indicador vulnerabilidade e governança formada pelo subindicador educação, trabalho e renda

Analisando a variável capacidade adaptativa (político-institucional) para os municípios de Alcantil e São João do Cariri comparando-os com o Brasil formado pelo subindicador Educação, Trabalho e renda composto pelos dados em percentual de pessoas em domicílios vulneráveis à pobreza e sem ensino fundamental completo (PDVPSEFC) e percentual de pessoas de 15 a 24 anos que não estudam, não trabalham e são vulneráveis (P NENTSV 15 a 24 anos) paras os anos de 1991; 2000 e 2010, respectivamente (Tabela 3).

Tabela 3: Indicador vulnerabilidade e governança formado pelo subindicador Educação, Trabalho e renda composto pelos dados em percentual de pessoas em domicílios vulneráveis à pobreza e sem ensino fundamental completo (PDVPSEFC) e pessoas de 15 a 24 anos que não estudam, não trabalham e são vulneráveis (PNENTSV 15 a 24 anos) do Brasil, comparado aos municípios do semiárido paraibano Alcantil e São João do Cariri paras os anos de 1991; 2000 e 2010.

\begin{tabular}{|c|c|c|c|c|c|c|}
\hline \multirow{2}{*}{$\begin{array}{l}\text { Comparativo do Brasil } \\
\text { com Municípios } \\
\text { estudados }\end{array}$} & \multicolumn{6}{|c|}{ Indicador vulnerabilidade e governança formado pelo subindicador Educação, Trabalho e renda } \\
\hline & $\begin{array}{l}\text { \% PDVPSEFC } \\
\text { (1991) }\end{array}$ & $\begin{array}{l}\text { \% PDVPSEFC } \\
(2000)\end{array}$ & $\begin{array}{l}\text { \% PDVPSEFC } \\
(2010)\end{array}$ & $\begin{array}{lr}\% & \text { PNENTSV } 15 \\
\text { a } 24 & \text { anos } \\
(1991) & \end{array}$ & $\begin{array}{lr}\% & \text { PNENTSV } 15 \\
\text { a } 24 & \text { anos } \\
(2000) & \end{array}$ & 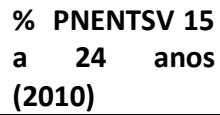 \\
\hline Brasil & 20,38 & 29,75 & 13,46 & -- & 31,3 & 33,34 \\
\hline Alcantil (PB) & 43,99 & 68,92 & 35,62 & -- & 34,03 & 36,03 \\
\hline São João do Cariri (PB) & 35,98 & 53,43 & 24,63 & -- & 31,97 & 31,1 \\
\hline
\end{tabular}

Pode-se observar que para os municípios de Alcantil e São João do Cariri, assim como para o Brasil, quando se fez o comparativo entre 1991 e 2000 os percentuais aumentaram de 1991 para 2000 levando em consideração o percentual de pessoas em domicílios vulneráveis à pobreza e sem ensino fundamental completo (Tabela 3). Isso significar dizer que de 1991 a 2000 aumentou o número de pessoas vulneráveis a pobreza e sem ensino fundamental completo, nos municípios e o Brasil, estando desta forma mais vulneráveis as condições de seca.

Esse aumento se deve a falta de políticas públicas e sociais de inclusão das pessoas e escolarização, visto que foi apenas em dezembro de 1996 que foi sancionada a Lei de diretrizes e bases da educação nacional LDB, ou seja , a escolarização das massas, em consonância com a formação oferecida pelas escolas de nível superior cujo acesso permanecia restrito às classes dominantes constituiria um dualismo no interior da sociedade a partir do qual se acreditava que o desenvolvimento nacional pudesse ser alavancado (MARCHELLI, 2014).

Já quando se comparou 2000 a 2010 esses percentuais de pessoas em domicílios vulneráveis à pobreza e sem ensino fundamental completo, reduziram para o Brasil, Alcantil e São João do Cariri, contudo, ainda com percentagens elevadas, em especial para São João do Cariri com 35,62\% (Tabela 3). Essa redução implica dizer que foram adotadas em nível de Brasil e municípios medidas que visam a mitigar essa vulnerabilidade da população.

Quando se analisou o percentual de pessoas de 15 a 24 anos que não estudam, não trabalham e são vulneráveis (PNENTSV 15 a 24 anos) nos anos de 1991, 2000 e 2010, para o Brasil, Alcantil e São João do Cariri, não foram obtidos dados dos anos de 1991, contudo quando se comparou 2000 a 2010 observa-se 
que houve evolução no PNENTSV 15 a 24 anos (Tabela 3). Isso implica afirmar que as medidas de governança adotadas pelo Brasil e municípios estudados não são suficientes para retirar as pessoas da situação de vulnerabilidade, sendo necessárias mais ações inclusivas visando matricular essa faixa etária em escolas, além de criação de posto de trabalhos para essas pessoas.

Pressupõe-se ainda que o nível de instrução do indivíduo é um atributo capaz de diferenciar as ocupações, ou seja, qual emprego estará disponível além do ponto de vista do prestígio, da hierarquia e das remunerações (IBGE, 2018).

Indicador vulnerabilidade e governança formada pelos subindicadores mortalidade Infantil e probabilidade de sobrevivência de idosos

Quando se estudou o indicador demografia formado pelos subindicadores mortalidade infantil (MI) (Tabela 4), notou-se que em ambos os municípios houve queda neste indicador de 1991 a 2000, para Alcantil de 16,75\% e para São João do Cariri de 44,73\%. Já para, 2000 comparado a 2010 a diminuição do percentual em Alcantil foi maior quando comparado às épocas anteriores, sendo de 50,0\%. E para São João do Cariri a diminuição foi de 49,3\%. Para o Brasil essa redução foi de 31,5\% e 45,37\%, respectivamente para 1991 comparado a 2000 e 2000 a 2010 (Tabela 4).

Tabela 4: Indicador demografia formado pelos subindicadores mortalidade Infantil (MI) e probabilidade de sobrevivência de idosos (PS) do Brasil, comparado aos municípios do semiárido paraibano Alcantil e São João do Cariri paras os anos de 1991; 2000 e 2010

\begin{tabular}{|l|l|l|l|l|l|l|}
\hline $\begin{array}{l}\text { Comparativo do Brasil com } \\
\text { Municípios estudados }\end{array}$ & \multicolumn{4}{l}{$\begin{array}{l}\text { Indicador demografia formado pelos subindicadores mortalidade Infantil e probabilidade } \\
\text { de sobrevivência de idosos }\end{array}$} \\
\cline { 2 - 7 } & \% MI (1991) & \% MI (2000) & \% MI (2010) & $\begin{array}{l}\text { \% PS } \\
\text { (1991) }\end{array}$ & $\begin{array}{l}\text { \% PS } \\
\text { (2000) }\end{array}$ & $\begin{array}{c}\text { \% PS } \\
\text { (2010) }\end{array}$ \\
\hline Brasil & 44,68 & 30,57 & 16,7 & 70,93 & 77,63 & 84,05 \\
\hline Alcantil (PB) & 61,9 & 51,53 & 24,7 & 66,2 & 67,2 & 83,37 \\
\hline São João do Cariri (PB) & 70,08 & 38,73 & 19,6 & 63,17 & 73,43 & 86,38 \\
\hline
\end{tabular}

Esses dados demonstram que a queda na mortalidade infantil nos dois municípios ao logo dos anos foi visível. Possivelmente em decorrência de ações ligadas a governança como o programa saúde da família que iniciou suas atividades em 1994, visando o atendimento as gestantes e crianças em situação de vulnerabilidade em vários municípios brasileiros, além de programas de erradicação da pobreza, fome zero, bolsa família entre outros (CERVATO-MANCUSO et al., 2012).

Para o subindicador probabilidade de sobrevivência de idosos (\%PS), evidencia-se que tanto de 1991 a 2000 quanto de 2000 a 2010 houve um aumento na \%PS isto em nível de Brasil e dos municípios do semiárido paraibano estudados (Tabela 4). Fato este que se justifica devido ao aumento da expectativa de vida dos idosos.

Contudo, vale destacar que o aumento da expectativa de vida apresenta duas facetas. Por um lado, reflete mudanças culturais e avanços obtidos em relação à saúde e às condições de vida, tais como: redução da taxa de fecundidade, queda da mortalidade infantil, hábitos alimentares mais saudáveis e maior cuidado com o corpo. Por outro, aponta para a possibilidade do/a idoso/a ser acometido por doenças degenerativas e crônicas, que o/a torna sem autonomia, ou seja, dependente de cuidados de alguém (KÜCHEMANN, 2012). 


\section{Indicador IDHM formado pelos subindicadores IDHM}

Ao estudar a variável capacidade adaptativa (político-institucional) indicador Índice de Desenvolvimento Humano Municipal - IDHM, para o Brasil, Alcantil e São João do Cariri comparando-se os anos de 1991 a 2000 e 2000 a 2010 (Tabela 5), é possível constatar que houve um acréscimo no IDHM de 1991 a 2000, correspondendo a 19,44; 21,32 e 24,62\% e de 2000 a 2010 15,81; 29,41 e 25,56\%, respectivamente, tanto a em nível de Brasil quanto dos munícipios (Tabla 5). O que implica em dizer que ao longo dos anos observaram-se melhorias no Brasil e seus municípios.

Tabela 5: Indicador IDHM do Brasil, comparado aos municípios do semiárido paraibano Alcantil e São João do Cariri paras os anos de 1991; 2000 e 2010.

\begin{tabular}{|l|l|l|l|}
\hline \multirow{2}{*}{$\begin{array}{l}\text { Comparativo do Brasil com } \\
\text { Municípios estudados }\end{array}$} & \multicolumn{4}{l|}{ Indicador IDHM formado pelos subindicadores IDHM } \\
\cline { 2 - 4 } & IDHM (1991) & IDHM (2000) & IDHM (2010) \\
\hline Brasil & 0,493 & 0,612 & 0,727 \\
\hline Alcantil (PB) & 0,321 & 0,408 & 0,578 \\
\hline São João do Cariri (PB) & 0,349 & 0,463 & 0,622 \\
\hline
\end{tabular}

Contudo, de acordo com (PNUD et al., 2013) O IDHM é considerado Muito baixo - entre 0,0 e 0,499; Baixo - entre 0,500 e 0,599; Médio - entre 0,600 e 0,699; Alto - entre 0,700 e 0,799 e Muito alto - entre 0,8000 e 1,0. Pode-se observa desta forma que embora com aumentos no IDHK no Brasil e nos municípios em 1991 o IDHM do Brasil e municípios este muito baixo, em 2000 apenas o Brasil possui IDHM considerado médio e em 2010 o Brasil tem IDHM muito alto, Alcantil baixo e São João do Cariri Alto. O Índice de Desenvolvimento Humano Municipal apresenta, de maneira quantitativa, a situação dos municípios no que diz respeito à educação (escolaridade), longevidade (expectativa de vida, que possui estreitas relações com investimentos na área da saúde) e renda.

\section{Indicador renda formado pelos subindicadores pobreza}

Ao estudar a variável sensibilidade (socioeconômica) composta pelo indicador renda e formado pelo subindicador Pobreza, levando em consideração o percentual de indivíduos extremamente pobres (IEP) e percentual de indivíduos de vulneráveis à pobreza (PIVP) do Brasil, comparado aos municípios do semiárido paraibano Alcantil e São João do Cariri paras os anos de 1991; 2000 e 2010 (Tabela 6), observa-se que houve redução no percentual de indivíduos extremamente pobres para o Brasil de 1991 a 2000 em 33\%. Para o município de Alcantil foi verificado leve aumento dos indivíduos extremamente pobres e em São João do Cariri foi constatada redução em 62\% quando comparados os anos de 19991 a 2000(Tabela 6).

Quando se observou os percentuais de indivíduos extremamente pobres (IEP) de 2000 a 2010, foi verificada redução de 46; 40 e 33\%, respectivamente para Brasil, Alcantil e São João do Cariri (Tabela 6). No entanto, apesar da redução da pobreza ser também uma função de variáveis como a oferta de vagas no mercado formal de trabalho (ARAÚJO et al., 2015), aumento da escolarização (MENEZES FILHO et al., 2015) e da implementação de programas focalizados de transferência de renda (SOARES et al., 2015), benefícios de substituição de renda como o benefício de prestação continuada - BPC também cumprem um importante papel na diminuição da concentração de pobreza regional. 
Tabela 6: Indicador renda formado pelos subindicadores pobreza composto por percentual de indivíduos extremamente pobres (IEP) e percentual de indivíduos vulneráveis à pobreza (PIVP) do Brasil, comparado aos municípios do semiárido paraibano Alcantil e São João do Cariri paras os anos de 1991; 2000 e 2010.

\begin{tabular}{|l|l|l|l|l|l|l|}
\hline $\begin{array}{l}\text { Comparativo } \\
\text { do Brasil com } \\
\begin{array}{l}\text { Municípios } \\
\text { estudados }\end{array}\end{array}$ & \% IEP (1991) & \% IEP (2000) & \% IEP (2010) & \% PIVP (1991) & \% PIVP (2000) & $\begin{array}{c}\text { \% PIVP } \\
\text { (2010) }\end{array}$ \\
\cline { 2 - 7 } & & & & & & \\
\hline Brasil & 18,64 & 12,48 & 6,62 & 58,53 & 48,39 & 32,56 \\
\hline Alcantil (PB) & 35,62 & 36,29 & 21,64 & 92,64 & 85,99 & 66,1 \\
\hline $\begin{array}{l}\text { São João do } \\
\text { Cariri (PB) }\end{array}$ & 51,38 & 19,3 & 12,91 & 89,62 & 76,05 & 54,39 \\
\hline
\end{tabular}

É importante salientar ainda que o segundo Ottonelli et al. (2014) o Ministério do Desenvolvimento Social e Combate à Fome (MDS), que é o designado da tarefa, estabeleceu o ponto de corte de $\mathrm{R} \$ 70,00$ per capita para definir famílias em situação de extrema pobreza e o dobro desse valor ( $R \$ 140,00)$ para definir a pobreza.

Ao analisar a o subindicador pobrezas mais especificamente o percentual de indivíduos vulneráveis à pobreza (PIVP), foi observado que de 1991 a 2000 houve uma redução de 17,3; 7,17 e 15,14\% para Brasil, Alcantil e São João do Cariri, respectivamente (Tabela 6). Essa redução foi mais expressiva quando se comparou 2000 a 2010, correspondendo a 32,71; 23,13 e 28,48\%, respectivamente, para Brasil, Alcantil e São João do Cariri (Tabela 6). Esses resultados corroboram para a constatação de que houve uma evolução significativa no tocante a retirada de pessoas da linha de extrema pobreza e diminuição de vulnerabilidade, fato que pode estar atrelada a ações de governança como Bolsa Família, BPC se destacam pela contribuição na redução do número de extremamente pobres.

\section{Indicador renda formado pelos subindicadores desigualdade}

Para a variável sensibilidade (socioeconômica) composta pelo indicador renda e formado pelo subindicador desigualdade, que envolve o percentual da renda apropriada pelos $80 \%$ mais pobres (PRA $80 \%$ mais pobres) e percentual da renda apropriada pelos 10\% mais ricos (PRA 10 mais ricos) do Brasil, comparado aos municípios do semiárido paraibano Alcantil e São João do Cariri para os anos de 1991; 2000 e 2010 (Tabela 7), observa-se que de 1991 a 2000 houve redução de 1\% para o Brasil, 4,11\% para Alcantil e acréscimo de $27,06 \%$ para São João do Cariri, isto para o percentual da renda apropriada pelos $80 \%$ mais pobres (PRA $80 \%$ mais pobres) (Tabela 7).

Tabela 7: Indicador renda formado pelos subindicadores desigualdade composto por Percentual da renda apropriada pelos $80 \%$ mais pobres (PRA $80 \%$ mais pobres) e percentual da renda apropriada pelos $10 \%$ mais ricos (PRA 10 mais ricos) do Brasil, comparado aos municípios do semiárido paraibano Alcantil e São João do Cariri paras os anos de 1991; 2000 e 2010.

\begin{tabular}{|c|c|c|c|c|c|c|}
\hline \multirow{2}{*}{$\begin{array}{ll}\text { Comparativo } & \text { do Brasil } \\
\text { com } & \text { Municípios } \\
\text { estudados } & \end{array}$} & \multicolumn{6}{|c|}{ Indicador renda formado pelos subindicadores desigualdade } \\
\hline & 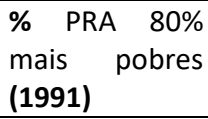 & 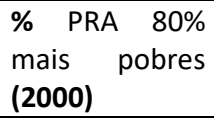 & $\begin{array}{lr}\% & \text { PRA } \\
\text { mais } & \text { pobres } \\
(2010) & \\
\end{array}$ & 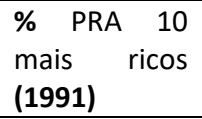 & 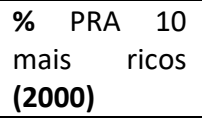 & $\begin{array}{l}\text { \% PRA } 10 \\
\text { mais ricos } \\
(\mathbf{2 0 1 0 )}\end{array}$ \\
\hline Brasil & 32,79 & 32,44 & 36,6 & 51,14 & 51,94 & 48,93 \\
\hline Alcantil (PB) & 52,7 & 50,53 & 50,27 & 30,73 & 30,81 & 29,36 \\
\hline São João do Cariri (PB) & 35,79 & 49,07 & 43,78 & 49,73 & 35,6 & 41,92 \\
\hline
\end{tabular}

Em relação a comparação de 2000 a 2010 para o fator percentual da renda apropriada pelos $80 \%$ 
mais pobres (PRA $80 \%$ mais pobres), observa-se que a nível de Brasil o aumento foi de $11 \%$, para Alcantil e São João do Cariri houve redução de 0,5\% e 10,7\%, respectivamente (Tabela 7). Estes dados evidenciam a concentração de renda em nível de Brasil para os mais ricos, tornando a população em maior número cada dia mais pobre.

Ao avaliarmos a situação dos municípios do semiárido paraibano e do Brasil para o percentual da renda apropriada pelos 10\% mais ricos, nota-se que de 1991 a 2000 houve aumento da renda para os mais ricos no Brasil e em Alcantil, ao passo que São João do Cariri obteve um decréscimo. Já quando se analisou de 2000 a 2010 ocorreu redução para o Brasil e Alcantil, no entanto São João do Cariri teve acréscimo no percentual da renda apropriada pelos $10 \%$ mais ricos (Tabela 7).

Medeiros et al. (2013) afirmam que uma grande parte dessa diferença observada ao longo dos anos está relacionada com a geração de emprego no setor público, atual - salários - ou passado - previdência do funcionalismo civil e militar. Nesse sentido, apenas $11 \%$ dos pagamentos são dirigidos à metade mais pobre da população. A concentração é tal que a soma dos pagamentos do Estado para os $5 \%$ mais ricos da população é $38 \%$ maior do que a soma de todos os pagamentos feitos à grande maioria formada pelos $80 \%$ mais pobres, correspondendo a $32 \%$. Estes resultados não se alteram substantivamente quando impostos diretos são descontados da renda das famílias.

\section{Indicador trabalho formado pelo subindicador escolaridade}

A variável sensibilidade dentro do contexto socioeconômico para o indicador trabalho composto pelo subindicador escolaridade formado percentual dos ocupados com ensino médio completo - 18 anos ou mais (POEMC) e percentual dos ocupados com ensino superior completo - 18 anos ou mais (POESC) do Brasil, comparado aos municípios do semiárido paraibano Alcantil e São João do Cariri paras os anos de 1991; 2000 e 2010 se encontram na Tabela 8.

Nota-se que em 1991 não foi obtido os dados para percentual dos ocupados com ensino médio completo - 18 anos ou mais (POEMC), ao passo que em 2000 o Brasil teve maior percentual de pessoas ocupadas e com ensino médio superior a São João do Cariri e este superior a Alcantil (Tabela 8). Quando se comparou 2000 a 2010 observou-se acréscimo para este índice para o Brasil e os municípios do semiárido paraibano (Tabela 8). Assim, fica evidente que houve ações de governança para este período o que contribui para redução da situação de vulnerabilidade a seca desses municípios.

Dos empregos formais disponíveis cerca $67,5 \%$ dos trabalhadores empregados haviam, pelo menos, concluído o ensino médio, independentemente de estarem no ensino superior ou de o terem concluído (IBGE, 2016). Logo, no mercado formal, é bem maior a presença de trabalhadores com o ensino médio completo. Assim, no conjunto geral de trabalhadores ocupados no mercado, seja na informalidade ou com carteira assinada, a presença de portadores de certificação de ensino médio é de apenas 50\%, mas, no mercado formal, este percentual chega a $67,5 \%$.

O indicador trabalho atrelado ao percentual dos ocupados com ensino superior completo - 18 anos ou mais (POESC) quando se comparou 1991 a 2000 e de 2000 a 2010, foi verificado aumento, ou seja, ao 
longo dos anos se elevou o número de indivíduos com curso superior no mercado de trabalho (Tabela 8).

Tabela 8: Indicador trabalho formado pelo subindicador escolaridade composto por percentual dos ocupados com ensino médio completo - 18 anos ou mais (POEMC) e percentual dos ocupados com ensino superior completo - 18 anos ou mais (POESC) do Brasil, comparado aos municípios do semiárido paraibano Alcantil e São João do Cariri paras os anos de 1991; 2000 e 2010.

\begin{tabular}{|l|l|l|l|l|l|l|}
\hline $\begin{array}{l}\text { Comparativo do Brasil com } \\
\text { Municípios estudados }\end{array}$ & \multicolumn{3}{|l|}{ Indicador trabalho formado pelo subindicador escolaridade } \\
\cline { 2 - 8 } & $\begin{array}{l}\text { \% POEMC } \\
\mathbf{( 1 9 9 1 )}\end{array}$ & $\begin{array}{l}\text { \% POEMC } \\
\mathbf{( 2 0 0 0 )}\end{array}$ & $\begin{array}{l}\text { \% POEMC } \\
\mathbf{( 2 0 1 0 )}\end{array}$ & $\begin{array}{l}\text { \% POESC } \\
\mathbf{( 1 9 9 1 )}\end{array}$ & $\begin{array}{l}\text { \% POESC } \\
\mathbf{( 2 0 0 0 )}\end{array}$ & $\begin{array}{l}\text { \% } \\
\text { POESC } \\
(\mathbf{2 0 1 0})\end{array}$ \\
\hline Brasil & 0 & 30,84 & 44,91 & 0 & 7,97 & 13,19 \\
\hline Alcantil (PB) & -- & 4,25 & 19,66 & -- & -- & 3,61 \\
\hline São João do Cariri (PB) & -- & 16,34 & 28,25 & -- & 1,06 & 6,61 \\
\hline
\end{tabular}

De acordo com IBGE (2016) para se ter uma ideia do nível de seletividade estabelecido no mercado de trabalho seja ele formal ou mesmo informal brasileiro, ao se considerar a escolarização dos indivíduos se observa que, entre os anos de 2004 e 2014, a população ocupada cresceu de 82,7 milhões para 98,1 milhões, com um incremento de $18,6 \%$. Neste mesmo intervalo de tempo a população ocupada detentora do ensino médio completo ou maior escolarização cresceu de 28,7 milhões para cerca de 49,3 milhões, o que representa um aumento da ordem de $71,8 \%$. Ou seja, o percentual de crescimento de pessoas ocupadas e detentoras do ensino médio foi quase quatro vezes maior que o índice de crescimento do quantitativo das pessoas ocupadas (OLIVEIRA, 2018). Fato este que corrobora com os dados percentuais obtidos neste trabalho, avaliando-se os anos de 1991, 2000 e 2010, respectivamente.

\section{Indicador trabalho formado pelo subindicador setor}

Indicador trabalho, subindicador setor formado pelo percentual dos ocupados no setor agropecuário - 18 anos ou mais (POSA) e percentual dos ocupados na indústria de transformação - 18 anos ou mais (POIT) do Brasil, comparado aos municípios do semiárido paraibano Alcantil e São João do Cariri paras os anos de 1991; 2000 e 2010 encontram-se na Tabela 9. É possível constatar que para ambos os fatores (POSA) e (POIT) no ano de 1991 não se consegui obter os dados.

Comparando-se o ano de 2000 a 2010 houve redução de 22 e $27 \%$ para Brasil e Alcantil no tocante ao percentual dos ocupados no setor agropecuário - 18 anos ou mais (POSA), no entanto, para São João do Cariri houve acréscimo de pessoas ocupadas de 2,21\% (Tabela 9). Ferreira (2010) afirma que a baixa produtividade é a principal causa do atraso, ou seja, da vulnerabilidade das pessoas que vivem no semiárido, existindo consenso de que a diferença da produtividade total dos fatores explica uma grande parte da diferença de renda, ou seja, uma área ou localidade é mais pobre porque é muito menos eficiente em organizar a sua produção e empregar os insumos, além da geração de emprego e renda. Isto é evidente nos dados obtidos, visto que se têm municípios com redução no número de indivíduos ocupados e existe municípios com aumento nesse número.

Já com relação ao percentual dos ocupados na indústria de transformação - 18 anos ou mais (POIT) nota-se que não foram obtidos dados de 1991, e quando se comparou 2000 a 2010 foi possível notar que para o Brasil houve uma redução do POIT, já para Alcantil e São João do Cariri houve um acréscimo percentual 
de 68 e 9\%, respectivamente (Tabela 9).

Tabela 9: Indicador trabalho formado pelo subindicador setor composto por percentual dos ocupados no setor agropecuário - 18 anos ou mais (POSA) e percentual dos ocupados na indústria de transformação - 18 anos ou mais (POIT) do Brasil, comparado aos municípios do semiárido paraibano Alcantil e São João do Cariri paras os anos de 1991; 2000 e 2010.

\begin{tabular}{|l|l|l|l|l|l|l|l|}
\hline \multirow{2}{*}{$\begin{array}{l}\text { Comparativo do Brasil com Municípios } \\
\text { estudados }\end{array}$} & \multicolumn{4}{|l|}{ Indicador trabalho formado pelo subindicador setor } \\
\cline { 2 - 8 } & $\begin{array}{l}\text { \% POSA POSA } \\
\mathbf{( 1 9 9 1 )}\end{array}$ & $\begin{array}{l}\mathbf{\%} \text { POSA } \\
\mathbf{( 2 0 0 0 )}\end{array}$ & $\begin{array}{l}\text { \% POIT } \\
\mathbf{( 2 0 1 0 )}\end{array}$ & $\begin{array}{l}\text { \% POIT } \\
\mathbf{( 1 9 9 1 )}\end{array}$ & $\begin{array}{l}\text { \% POIT } \\
(\mathbf{2 0 0 0 )}\end{array}$ \\
\hline Brasil & 0 & 17,4 & 13,55 & 0 & 13,56 & 11,92 \\
\hline Alcantil (PB) & -- & 58,93 & 42,97 & -- & 5,55 & 17,71 \\
\hline São João do Cariri (PB) & -- & 47,78 & 48,86 & -- & 2,37 & 2,63 \\
\hline
\end{tabular}

Cruz et al. (2011) ao estudarem a dinâmica do emprego industrial no Brasil entre 1990 e 2009: uma visão regional da desindustrialização afirmam que para regiões como o nordeste do Brasil, geralmente atraem indústrias com menor índice tecnológico, dado a isto os municípios do semiárido paraibano obtiveram acréscimo no número de indivíduos ocupados na indústria, uma vez que estas possuem menor nível tecnológico o que propicia a inserção de maior número de pessoas.

Indicador habitação formado pelo subindicador porcentagem da população com água encanada, população em domicílios com coleta de lixo e população em domicílios com energia elétrica

No contexto da variável sensibilidade (socioeconômica) para o indicador habitação formado pelo subindicador porcentagem da população com água encanada- PPDCAE, população em domicílios com coleta de lixo - PPDCL e população em domicílios com energia elétrica - PPDCEE do Brasil, comparado aos municípios do semiárido paraibano Alcantil e São João do Cariri paras os anos de 1991; 2000 e 2010 (Tabela 10), verificar-se que para o componente porcentagem da população com água encanada quando se comparou 1991 a 2000, verificou-se para o Brasil e são João do Cariri acréscimo, em contrapartida para Alcantil o número de pessoas que receberam água encanada reduziu (Tabela 10).

Tabela 10: Indicador habitação formado pelo subindicador porcentagem da população com água encanada composto pelo percentual da população em domicílios com água encanada (PPDCAE), porcentagem da população em domicílios com coleta de lixo (PPDCL) e porcentagem da população em domicílios com energia elétrica (PPDCEE) do Brasil, comparado aos municípios do semiárido paraibano Alcantil e São João do Cariri paras os anos de 1991; 2000 e 2010.

\begin{tabular}{|c|c|c|c|c|c|c|c|c|c|}
\hline \multirow{2}{*}{$\begin{array}{l}\text { Comparativo } \\
\text { do Brasil } \\
\text { com } \\
\text { Municípios } \\
\text { estudados }\end{array}$} & \multicolumn{9}{|c|}{$\begin{array}{l}\text { Indicador habitação formado pelo subindicador porcentagem da população com água encanada, população em } \\
\text { domicílios com coleta de lixo e população em domicílios com energia elétrica }\end{array}$} \\
\hline & $\begin{array}{l}\% \\
\text { PPDCAE } \\
(\mathbf{1 9 9 1 )}\end{array}$ & $\begin{array}{l}\% \\
\text { PPDCAE } \\
(\mathbf{2 0 0 0 )}\end{array}$ & $\begin{array}{l}\% \\
\text { PPDCAE } \\
\text { (2010) }\end{array}$ & $\begin{array}{l}\text { \% PPDCL } \\
\text { (1991) }\end{array}$ & $\begin{array}{l}\text { \% PPDCL } \\
\text { (2000) }\end{array}$ & $\begin{array}{l}\text { \% PPDCL } \\
\text { (2010) }\end{array}$ & $\begin{array}{l}\% \\
\text { PPDCEE } \\
\text { (1991) }\end{array}$ & $\begin{array}{l}\% \\
\text { PPDCEE } \\
(\mathbf{2 0 0 0 )}\end{array}$ & $\begin{array}{l}\% \\
\text { PPDCEE } \\
(\mathbf{2 0 1 0 )}\end{array}$ \\
\hline Brasil & 71,31 & 81,79 & 92,72 & 77,93 & 91,12 & 97,02 & 84,84 & 93,46 & 98,58 \\
\hline Alcantil (PB) & 13,36 & 0,49 & 2,94 & $\begin{array}{l}- \\
\end{array}$ & 93,5 & 98,76 & 41,5 & 86,76 & 99,3 \\
\hline $\begin{array}{l}\text { São João do } \\
\text { Cariri (PB) }\end{array}$ & 41,62 & 46,65 & 68,69 & 21,71 & 91,87 & 99,69 & 60,17 & 95,59 & 99,5 \\
\hline
\end{tabular}

Já quando se comparou 2000 a 2010 houve aumento para o Brasil, Alcantil e São João do Cariri, correspondendo a 11,7; 83,3 e 32,0\%, respectivamente para PPDCAE (Tabela 10). No entanto, mesmo com esse aumento no número de domicílios que recebem água encanada, deve-se atentar que um dos elementos causadores das desigualdades no acesso à água devem agregar aspectos contextuais de natureza macro, nas perspectivas demográfica, socioeconômica, política e cultural, e micro, que refletem as características 
intrínsecas à dinâmica local e às relações que se estabelecem cotidianamente na forma de se dispor do recurso e de utilizá-lo, e tendo em vista o aumento das desigualdades no acesso à água e a concentração do déficit em determinados grupos populacionais.

Para a WHO et al. (2014) as populações mais pobres permanecem à margem de muitas das melhorias observadas nos últimos anos. Assim, os residentes nos países em desenvolvimento e nas áreas rurais, os mais pobres e as minorias étnicas, religiosas e as mulheres, são mais propensos a não terem acesso a fontes melhoradas de água e a serviços de esgotamento sanitário.

Com relação ao fator população em domicílios com coleta de lixo - PPDCL ao se comparar 1991 a 2000 em nível de Brasil, Alcantil e São Joao do Cariri houve aumento no número de domicílios que recebem coleta de lixo. Para 2000 comparado a 2010 também se verificou acréscimos no PPDCL (Tabela 10). No entanto, mesmo com este avanço deve ter a destinação correta dos resíduos em aterros sanitário, contudo, a maioria dos municípios brasileiros ainda destina seus resíduos a vazadouros a céu aberto, ou seja, os ditos lixões e a aterros controlados, porem de forma inadequada, sendo que mais de $70 \%$ dos municípios utilizam tais formas inadequadas de disposição final (IBGE, 2010).

O parâmetro população em domicílios com energia elétrica - PPDCEE, observou-se uns acréscimos de 1991 a 2000 e de 2000 a 2010, para o Brasil, Alcantil e São João do Cariri (Tabela 10). Fato que se deve a adoção de programas como Luz para Todos do governo federal.

\section{Indicador educação formado pelo subindicador Evolução da população exposta ao analfabetismo}

Ao estudar a variável exposição (sociocultural) indicador educação formado pelo subindicador Evolução da população exposta ao analfabetismo composto pela taxa de analfabetismo - 11 a 14 anos (TA 11 a 14 anos) e taxa de analfabetismo - 25 a 29 anos (TA 25 a 29 anos) do Brasil, comparado aos municípios do semiárido paraibano Alcantil e São João do Cariri paras os anos de 1991; 2000 e 2010 (Tabela 11), é possível verificar que o analfabetismo composto pela taxa de analfabetismo - 11 a 14 anos e a taxa de analfabetismo - 25 a 29 anos, reduziu se comparando 1991 a 2000 e 2000 a 2010 para o Brasil, Alcantil e São João do Cariri, respectivamente (Tabela 11).

Tabela 11: Indicador educação formado pelo subindicador Evolução da população exposta ao analfabetismo composto pela taxa de analfabetismo - 11 a 14 anos (TA 11 a 14 anos) e taxa de analfabetismo - 25 a 29 anos (TA 25 a 29 anos) do Brasil, comparado aos municípios do semiárido paraibano Alcantil e São João do Cariri paras os anos de 1991; 2000 e 2010.

\begin{tabular}{|c|c|c|c|c|c|c|}
\hline \multirow{2}{*}{$\begin{array}{l}\text { Comparativo do Brasil com } \\
\text { Municípios estudados }\end{array}$} & \multicolumn{6}{|c|}{ Indicador educação formado pelo subindicador Evolução da população exposta ao analfabetismo } \\
\hline & $\begin{array}{l}\text { TA } 11 \text { a } 14 \\
\text { anos (1991) }\end{array}$ & $\begin{array}{l}\text { TA } 11 \text { a } 14 \\
\text { anos (2000) }\end{array}$ & $\begin{array}{l}\text { TA } 11 \text { a } 14 \\
\text { anos (2010) }\end{array}$ & $\begin{array}{l}\text { TA } 25 \text { a } 29 \\
\text { anos (1991) }\end{array}$ & $\begin{array}{l}\text { TA } 25 \text { a } 29 \\
\text { anos (2000) }\end{array}$ & $\begin{array}{l}\text { TA } 25 \text { a } 29 \\
\text { anos (2010) }\end{array}$ \\
\hline Brasil & 16,08 & 6,26 & 3,24 & 12,7 & 8,02 & 3,96 \\
\hline Alcantil (PB) & 37,33 & 7,66 & 6,31 & 46,4 & 26,04 & 13,17 \\
\hline São João do Cariri (PB) & 28,49 & 6,3 & 4,85 & 24,11 & 14,85 & 8,25 \\
\hline
\end{tabular}

De acordo com IBGE (2016) o índice de analfabetismo na população de 15 anos ou mais nos anos de 2010 era de 9,7\%; cerca de 14 milhões de pessoas num universo de 190 milhões de habitantes, contudo, mesmo o percentual sendo reduzido ao longo dos anos, o número total de analfabetos aumentou de 6,348 milhões para 16.295 milhões em cem anos. Isso implica dizer que as medidas que visam mitigar essa 
vulnerabilidade ainda não conseguem abranger um grande número de pessoas.

\section{Indicador educação formado pelo subindicador Porcentagem da escolaridade}

Ao analisarmos a variável exposição (sociocultural, indicador educação formado pelo subindicador porcentagem da escolaridade composto pelo percentual dos ocupados com ensino fundamental completo 18 anos ou mais (POCEFC 18 anos ou mais) e percentual dos ocupados com ensino médio completo - 18 anos ou mais (POCEMC 18 anos ou mais) do Brasil, comparado aos municípios do semiárido paraibano Alcantil e São João do Cariri paras os anos de 1991; 2000 e 2010 (Tabela 11), pode-se notar que quando se compara 1991 a 2000 e 2000 a 2010 houve acréscimo percentual para POCEFC 18 anos ou mais e POCEMC 18 anos ou mais no Brasil, Alcantil e São João do Cariri, respectivamente (Tabela 11).

Tabela 12: Indicador educação formado pelo subindicador porcentagem da escolaridade composto pelo percentual dos ocupados com ensino fundamental completo - 18 anos ou mais (POCEFC 18 anos ou mais) e percentual dos ocupados com ensino médio completo - 18 anos ou mais (POCEMC 18 anos ou mais) do Brasil, comparado aos municípios do semiárido paraibano Alcantil e São João do Cariri paras os anos de 1991; 2000 e 2010.

\begin{tabular}{|c|c|c|c|c|c|c|}
\hline \multirow{2}{*}{$\begin{array}{l}\text { Comparativo do Brasil } \\
\text { com Municípios } \\
\text { estudados }\end{array}$} & \multicolumn{6}{|c|}{ Indicador educação formado pelo subindicador Porcentagem da escolaridade } \\
\hline & $\begin{array}{l}\text { POCEFC } 18 \\
\text { anos ou mais } \\
(\mathbf{1 9 9 1 )}\end{array}$ & $\begin{array}{l}\text { POCEFC } 18 \\
\text { anos ou mais } \\
(\mathbf{2 0 0 0 )}\end{array}$ & $\begin{array}{l}\text { POCEFC } 18 \\
\text { anos ou mais } \\
\text { (2010) }\end{array}$ & $\begin{array}{l}\text { POCEMC } 18 \\
\text { anos ou mais } \\
(1991)\end{array}$ & $\begin{array}{l}\text { POCEMC } 18 \\
\text { anos ou mais } \\
(\mathbf{2 0 0 0 )}\end{array}$ & $\begin{array}{l}\text { POCEMC } 18 \\
\text { anos ou mais } \\
\text { (2010) }\end{array}$ \\
\hline Brasil & 0 & 46,47 & 62,29 & 0 & 30,84 & 44,91 \\
\hline Alcantil (PB) & -- & 11,28 & 34,8 & -- & 4,25 & 19,66 \\
\hline São João do Cariri (PB) & -- & 24,7 & 41,33 & -- & 16,34 & 28,25 \\
\hline
\end{tabular}

Esse aumento em ocupados seja com ensino fundamental completo e médio completo, estão relacionados a geração de emprego no setor formal e mesmo informal. De acordo com essa entidade, estimase que o tamanho do setor informal no Brasil é de cerca de $39 \%$ do PIB, e que o valor total de impostos perdidos devido à informalidade seja de USD 280 bilhões (ULYSSEA et al., 2010).

\section{CONCLUSÕES}

Os indicadores de vulnerabilidade à seca e governança desenvolvidas são capazes de diagnosticar a situação da população da região semiárida paraibana, e apontar quais estratégias de governança tem sido utilizado para mitigar a vulnerabilidade. Os municípios do Cariri paraibano, mais precisamente Alcantil e São João do Cariri quando se compara 1991 a 2000 e 2000 a 2010, são considerados vulneráveis a seca, pois as estratégias de governança a seca adotas ainda não são suficientes para suprir todos os problemas. As principais estratégias de governança adotadas em Alcantil e São João do Cariri são Bolsa família, Benefício de prestação continuada, luz para todos, empregos em órgãos públicos e o programa saúde da família.

\section{REFERÊNCIAS}

ANDRADE, A. J. P.; SOUZA, C. R.; SILVA, N. M.. A vulnerabilidade e a resiliência da agricultura familiar em regiões semiáridas: o caso do Seridó Potiguar. CampoTerritório: Revista de Geografia Agrária, v.8, n.15, p.1-30, 2013. DOI: https://doi.org/10.14393/RCT

ANDRADE, J. A.; NUNES, M. A.. Acesso à água no SAB: uma análise das políticas públicas implementadas na região.
Revista Espinhaço (UFVJM), v.3, n.2, p.28-39, 2017.

ARAÚJO, N.; BARONE, L.; BRITO, M. A.. Mercado e mercantilização do trabalho no Brasil (1960-2010). In: ARRETCHE, M.. Trajetórias das Desigualdades: como o Brasil mudou nos últimos cinquenta anos. São Paulo: Unesp, 2015.

BARRETO, M. L.; TEIXEIRA, M. G.; BASTOS, F. I.; XIMENES, R. 
A.; BARATA, R. B.; RODRIGUES, L. C.. Successes and failures in the control of infectious diseases in Brazil: social and environmental context, policies, interventions, and research needs. Lancet, v.377, n.1, p.1877-1889, 2011. DOI: http://doi.org/10.1016/S0140-6736(11)60202-X

BHATTACHARYA, S.; DASS, A.. Vulnerability to drought, cyclones and floods in India. Nova Delhi: Winrock International, 2007.

BRASIL. Ministério do Meio Ambiente. Mapas Temáticos. Brasília: MMA, 2016

CACCIAMALI, M. C.; BARBOSA, A.. Desigualdades econômicas e sociais no Nordeste: Análise temática dos Estudos prospectivos sobre o desenvolvimento do Nordeste para o BNB. Fortaleza: IICA/BNB, 2014.

CERVATO-MANCUSO, A. M.; TONACIO, L. V.; SILVA, E. R.; VIEIRA, V. L.. A atuação do nutricionista na Atenção Básica à Saúde em um grande centro urbano. Ciência \& Saúde Coletiva, v.17, n.12, p.3289-3300, 2012. DOI: https://doi.org/10.1590/S1413-81232012001200014

CRUZ, B. O.; SANTOS, I. R. S.. Dinâmica do emprego industrial no Brasil entre 1990 e 2009: uma visão regional da desindustrialização. Rio de Janeiro: Ipea, 2011.

EL-ZEIN, A.; TONMOY, F. N.. Assessment of vulnerability to climate change using a multi-criteria outranking approach with application to heat stress in Sydney. Ecological Indicators, v.48, p.207-217, 2015. DOI: https://doi.org/10.1016/i.ecolind.2014.08.012

FERREIRA, P. C.. Eficiência e produtividade total dos fatores em Minas Gerais. Ensaios Econômicos, Rio de Janeiro, n.705, 2010.

FRANCISCO, P. R. M.. Classificação e mapeamento das terras para mecanização do Estado da Paraíba utilizando sistemas de informações geográficas. Dissertação (Mestrado em Manejo de Solo e Água) - Universidade Federal da Paraíba, Areia, 2010.

IBGE. Instituto Brasileiro de Geografia e Estatística. Censo Demográfico 2017. Rio de Janeiro: IBGE, 2017.

IBGE. Instituto Brasileiro de Geografia e Estatística. Pesquisa nacional de saneamento básico 2008. Rio de Janeiro: IBGE, 2010.

IBGE. Instituto Brasileiro de Geografia e Estatística. Síntese de Indicadores Sociais 2016: uma análise das condições de vida da população brasileira. Rio de Janeiro: IBGE, 2016.

IBGE. Instituto Brasileiro de Geografia e Estatística. Síntese de indicadores sociais: uma análise das condições de vida da população brasileira. Rio de Janeiro: IBGE, 2018.

IEA. International energy agency. World Energy Outlook 2015: Executive Summary. IEA, 2015.

IICA. Instituto Interamericano de Cooperação para a Agricultura. Universalização de acesso e uso da energia elétrica no meio rural brasileiro: ligações do Programa Luz para Todos. IICA, 2011.
KOOIMAN, J. G.. A social-political perspective. In: GROTE, J. R.; GBIKPI, B.. Participatory governance. Political and scietal implications. Opladen: Leske + Budrich, 2013. p.71-96.

KÜCHEMANN, B. A.. Envelhecimento populacional, cuidado e cidadania: velhos dilemas e novos desafios. Revista Sociedade e Estado, v.27, n.1, p.165 -180, 2012. DOI: https://doi.org/10.1590/S0102-69922012000100010

MARCHELLI, P. S.. Da LDB 4.024/61 ao debate contemporâneo sobre as bases curriculares nacionais. Revista e-Curriculum, v.12, n.3, p.1480-1511, 2014.

MARENGO, J. A. C. A.; NOBRE, J.; TOMASELLA, M. D.; OYAMA, G. S.; OLIVEIRA, R.; OLIVEIRA, H.; CAMARGO, L. M.. Variabilidade e mudanças climáticas no Semiárido Brasileiro. Recursos Hídricos em regiões áridas e semiáridas, Campina Grande, v.21, p.495-516, 2011. DOI: http://doi.org/10.1175/2007JCLI1600.1

MEDEIROS, M.; SOUZA, P. H. G. F.. Estado e Desigualdade de Renda no Brasil Fluxos de rendimentos e estratificação social. Revista brasileira de ciências sociais, v.28, n.83, p.141-239, 2013. DOI: https://doi.org/10.1590/S010269092013000300009

MENEZES FILHO, N.; KIRSCHBAUM, C.. Educação e Desigualdade no Brasil. In: ARRETCHE, M.. Trajetórias das Desigualdades: como o Brasil mudou nos últimos cinquenta anos. São Paulo: Unesp, 2015.

OLIVEIRA, P. C. P.. Universalização do acesso à energia eléctrica como vector de desenvolvimento econômico. Dissertação (Mestrado em Economia) - Universidade do Porto, Porto, 2013.

OLIVEIRA, R.. O ensino médio e a inserção juvenil no mercado de trabalho. Revista Trabalho Educação e Saúde, v.16 n.1, p.79-98, 2018. DOI: http://dx.doi.org/10.1590/1981-7746-sol00116

OTTONELLI, J.; MARIANO, J. L.. Pobreza multidimensional nos municípios da Região Nordeste. Revista de administração Pública, v.48, n.5, p.1253-1279, 2014. DOI: https://doi.org/10.1590/0034-76121724

PNUD; IPEA. Programa das Nações Unidas para o Desenvolvimento; Instituto de Pesquisa Econômica Aplicada, FJP. $O$ índice de desenvolvimento humano municipal brasileiro. Brasília: PNUD, 2013.

RAKODI, C.. Politics and performance: the implications of emerging governance arrangements for urban management approaches and information systems. Habitat International, v.27, n.4, p.523-547, 2013. DOI: https://doi.org/10.1016/S0197-3975(03)00004-3

SOARES, M. B.; GAGNON, A.; DOHERTY, R.. Conceptual elements of climate change vulnerability assessments: a review. International Journal of Climate Change Strategies and Management, v.4, n.1, p.6-35, 2012.

SOARES, S.; SOUZA, L. R.; SILVA, W. J.; SILVEIRA, F. G.. Perfil da Pobreza: Norte e Nordeste Rurais. Brasília: Centro Internacional de Políticas para o Crescimento Inclusivo, 2015. 
TARGINO, I.; MOREIRA, E. R. F.; ARAÚJO, N. M. U..

Desempenho da agropecuária paraibana na década de 2000.

Revista OKARA: Geografia em debate v.8, n.2, p.271-293.

2014.

ULYSSEA, G.; BARROS, R. P.. On the Empirical Content of the Formal-Informal Labor Market Segmentation Hypothesis.
Brazilian Review of Econometrics, v.30, n.2, p.289-310, 2010.

WHO; UNICEF. World Health Organization; United Nations Children's Fund. Progress on sanitation and drinking-water. WHO, 2014.

A CBPC - Companhia Brasileira de Produção Científica (CNPJ: 11.221.422/0001-03) detém os direitos materiais desta publicação. Os direitos referem-se à publicação do trabalho em qualquer parte do mundo, incluindo os direitos às renovações, expansões e disseminações da contribuição, bem como outros direitos subsidiários. Todos os trabalhos publicados eletronicamente poderão posteriormente ser publicados em coletâneas impressas sob coordenação da Sustenere Publishing, da Companhia Brasileira de Produção Científica e seus parceiros autorizados. Os (as) autores (as) preservam os direitos autorais, mas não têm permissão para a publicação da contribuição em outro meio, impresso ou digital, em português ou em tradução. 